\title{
Positive tourism precinct outcomes in developing countries
}

\author{
R. Moore \\ Anglia Ruskin University Chelmsford and Cambridge, UK
}

\begin{abstract}
Overriding goals and aims of improved and ongoing ecological performance arise when implementing 'sustainability' throughout the delivery process. This is seen where innovative organizations want their tourism developments to become accredited iconic master planned facilities. In a developing country using assessed world best practice planning, design, construction and operational principles has distinct advantages. An integrative process methodology leads to projects becoming great places to visit, to stay and to work. Adopting integrated economic and holistic approaches can result in decisions that provide long and short stay residents with healthy lifestyles and improved quality of life opportunities. These outcomes are closely linked to improvements in the built and natural environment so that it delivers for example privacy and quiet along with opportunities for safe and possible inspiring interaction with others. Also protection and regeneration of large areas of existing landscape encourages respect for the surrounding ecology and bio-diversity. As well they encourage equitable economic opportunities and growth. However reward and recognition go hand in hand with the approach. This paper reports on the use of an assessment framework tool engaged on several projects in China and Vietnam. The tool known as the EarthCheck Precinct Planning and Design Standard (PPDS) gave consideration to a perception that where positive development principles are being applied to mixed-use precincts there needs to be a means by which the outcomes of drivers can be assessed, benchmarked and certified as industry best practice for improved and on-going ecological performance betterment. The standard supports full integration of total development processes which aids delivery of balanced triple bottom line agendas.
\end{abstract}

Keywords: positive development, assessment, tool, reward and recognition. 


\section{Introduction and primary findings}

The aim of this paper is to report on the continuing diffusion of an international accreditation precinct and planning design standard (PPDS) into the travel and tourism industry. This latest phase involves the commercial usage of the standard which provides essential information for developers, planners and designers involved in a total development delivery process. The associated assessment reporting elaborates on the provision of a more rigorous and meaningful mechanisms of 'Sustainability Assessment' which is now a major goal [1]. This is primarily done by offering support through Key Performance Areas (KPA) and Sector Benchmarking Indicators (SBI) and actual measures. Described here is the linking of these to the crucial decision-making stages of a projects master planning and design with PPDS (see Figure 1), which is principally a framework management tool [2].

\section{Master Planning and Design}

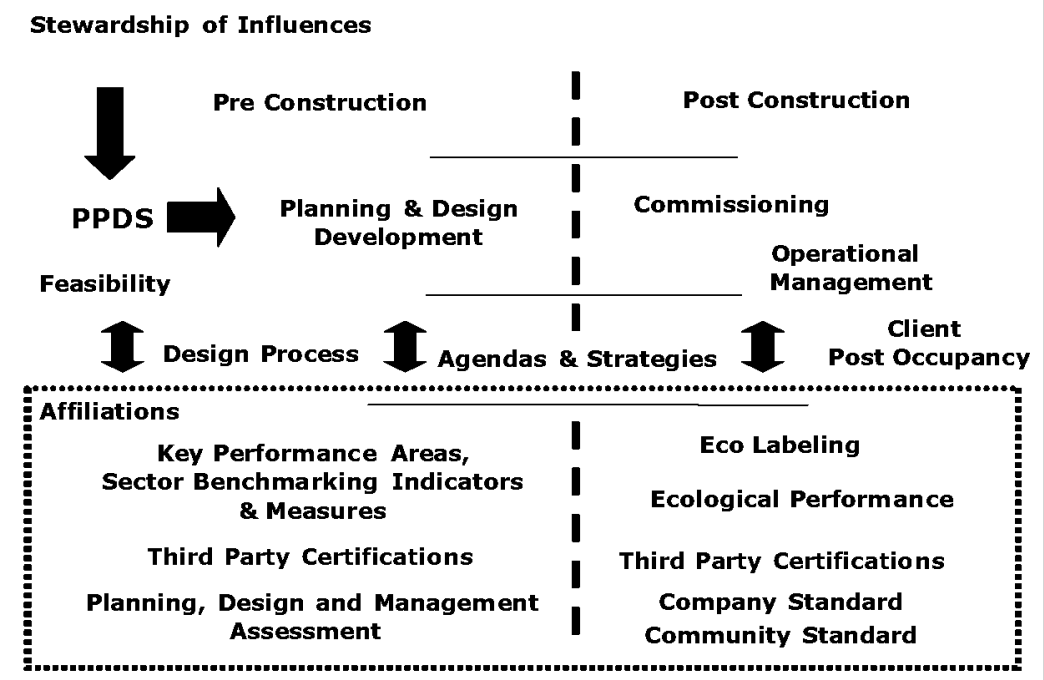

Figure 1: $\quad$ Framework management tool.

The resultant analysis of a number of schemes in two developing countries in the Australasia region (China and Vietnam) is being used to further establish the sagacity of process engagement with precinct development particularly those with travel and tourism infrastructure. It also provides additional evaluation of model use in assessing the sustainability of mixed use undertakings that is consistent with independent international third party methodologies of sustainable development accreditation. This is needed for there to be supplementary refinement of the integrated framework model and associated 
tools for a developing country. The aim is to better meet the needs of developers and independent external accreditation as the standard is more widely diffused into other international regions and markets.

Achieving ecological performance improvements on medium to large mixed use precincts is a significant outcome for any developer and associated stakeholders. It offers opportunities to mitigate or reduce environmental and social impacts, improve bio diversity, ensure economic viability and increase returns on capital. These gains are as important for a developing country as for a developed one. The research shows that accredited triple bottom line outcomes are possible in the developing world without significant compromise of sustainability principles. In fact it is conceivable that in some places and with an innovative and committed developer it will be easier than in more established regions and markets due to fewer regulatory and institutional barriers.

These assertions are made because the integrated standard provides organisations with planning and design frameworks, environmental and ecological mitigation measures, energy and water models, social and economic commitment guidelines and checklists. Much of the content of the tool evolving from a data base of other projects firmly aligned to and collecting information from facilities being built and operating in developing countries. This enables the assessment of the developments and their operations in terms of outcomes and overall enhancement of total ecological or 'triple bottom line' performance to be firmly placed geographically and virtually site specific.

Further for schemes to achieve an Industry Best Practice level they need to establish a set of 'Environmentally Sustainable Development' (ESD) related goals to assist in aligning development outcomes with ethical and socially responsible business principles. Many of these match those found in newly aspirational development documents created in developing countries, not least China and Vietnam. Much of the content is inspired by UN declarations and national visions [3]. The translation into policy and strategy is often very succinct, localised and pragmatic because of existing infrastructure limitations i.e. water and energy supply. Due in part because resultant legislative directives and regulations often benefit from understandings gained from reviewing more mature regulatory systems. These developed structures have had to make significant changes to accommodate growing calls for more targets driven sustainable development. The two countries have reflected this demand in their statutory processes but benefit from considerable retrospection. They also show a considerable willingness to engage with wide ranging international expertise that offers innovative integrated management and technical methodologies based on whole system process approaches.

\section{Research methodology and context}

The research reported on in this paper is facilitated by investigations into the management, planning and design processes of a number of medium to large mixed use precincts. The ensuing analysis of these actual in-time case studies provide insights into how major developments come to life, evolve and are undertaken. They are part of larger number of case studies providing an 
evidentiary base used for determining comparative outcomes. Use of multiple case studies generates a cross case analysis which is both descriptive and covers explanatory topics as recommended by [4]. This option recognizes that each of these developments has its own context and perspective. The large number accommodates and overcomes the uniqueness and artificial conditions surrounding case studies. In doing so they are able to provide a means to access highly pertinent information and understanding of real life phenomenon.

Case studies predominantly provide qualitative data but are still able to use quantitative input to add to an overall picture of outcomes [5,6]. Qualitative findings come into their own [7] when evaluating and developing the knowledge of how things worked on these case studies. From the lessons recorded it is possible that the observations on actual implementation of processes aid future precinct developments. This is due to these amplifications of good practice being formulated into amendment of this pragmatic framework model and tool which is already in use within the tourism development industry.

The actual case studies are mixed use precincts with an extensive mix of travel and tourism infrastructure and facilities. Their importance is not only scale but also the implementation timescales involved. All are underway and at various stages of the development process. On one of the projects major facilities (i.e. hotel, golf course, structural landscaping) have been completed and tourist occupancy is now underway.

Information flowing from the schemes is underwritten by the clients' own development teams. The projects were also targeted at several crucial areas of what have become major considerations for any sustainability agenda. They are 'Quality of Life' and ecological enhancement of a development and its surrounds. A further dynamic is that they are subject to the PPDS assessment and certification process. This provides a comparative assessment of employing a specific tool in different countries, geographical locations and demography and within dissimilar regulatory systems. Further they have important similarities despite variances in location, scale, nature and mix. These disparate features are not uncommon occurrences given the growth of tourism.

All of the case studies underwent an extensive independent third party assessment that utilised a significant number of practices. These include site visits, workshops, interviews and an array of investigative methods such as spreadsheets and checklists. The approaches aim at achieving transparent and relevant measurement of sustainability. Other measured factors have more to do with timescales and deliberate environmental, social and economic policies.

Crucially the major commonality aspects are as follows:

-

-

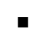


Data requirements to facilitate a PPDS appraisal are extensive and as with any proactive assessment tool the process is evidence hungry [8]. This facet of assessing a project is met by the client/developer's project planning and design team following directions from an independent accreditation assessor. The details supplied are used to corroborate and measure where practical predicted total development outcomes. They also inform expert judgements made regarding evaluation of predicted consequences and possible impacts against the suite of PPDS KPA's, indicators and measures. The initial overviews are provided by the project developer through a specific pre-qualification questionnaire that determines if the scheme is suitable for accreditation.

On acceptance into the PPDS process an assessment of the mixed-use precinct using PPDS KPA's, benchmarking indicators and measures takes place. To support expert opinion data/spread sheets are used to evaluate and determine how predicted values compare with industry best practice or norms. This comparative study route uses data collected over 10 years from similar resort operations around the Australasian and Caribbean regions [9]. It is in many cases location and geographical specific. The resultant matrix and in-depth reports are scheme discrete and provide the scored KPA best practice or industry norm outcomes of the assessor's findings. The resultant score identifies if the scheme has achieved industry best practice.

\section{PPDS: a framework model and tool for accreditation}

The accreditation procedure is formulated to be used from project inception and early planning and design stages of a development. It can also assess construction along with operational strategies and actual sequential activity. In essence it is a management framework for delivering sustainability agendas on developments. These should be integrated into the master plan as early as possible. This interjection allows for early detection, mitigation and/or enhancement of aspects of the total process which may impact on a schemes positive development [10]. It is not a rating tool but rather a continuing improvement journey map which allows the client-developer to respond to the uniqueness of the project's geographical and demographic location and socioeconomic profile [11].

The assessment methodology employed by the PPDS process is based on quantitative and qualitative modelling and continued evolution via testing and amendment where appropriate of relevant KPA's, indicators and associated measures. This is done by concurrent in-depth evaluation of the management, planning and design processes employed on other assessed and accredited developments. Many of these as previously noted have similar geographical location, adjacency and development profiles. PPDS identifies impacts and then evaluates how the project teams responded to the challenges resulting from seeking ecological progression. Whilst the standard primarily gives regard to projected precinct planning and design outcomes it also reviews certain facets of the interrelated construction and operational phases. This overview mainly regards the use of policy and implementation strategies that may mitigate or reduce actual impacts. It also considers possibilities regarding evolving 
community outcomes. This is a critical area because ensuing equitable social and economic results may mean the differences between long term precinct success and failure [11].

Crucially for verification it is sometimes possible to assess these later stages as areas of construction and structural infrastructure work on some projects has started, is underway or fully completed. Further as stated earlier on some precincts occupation by tourists and resort workers of facilities has started. This is not uncommon particularly regarding enabling and off-site works on large mixed use precincts or projects that involve existing facilities scheduled for possible renovation and refurbishment.

\section{Basis for assessment}

PPDS assessment of sustainability engages ten KPAs for evaluation of a project's progress towards improved ecological performance. The process consists of two stages; assessment and certification. Only master planned precincts providing measurable evidence during appraisal of their sustainability agenda directed at achieving sustainable development attain certification. The review focuses on sustainable development contexts, KPA's, benchmarking indicators and measures. All are used to evaluate the predicted outcomes of a project.

The primary context and related KPAs are:

- Master plans and design details;

- Building location and siting;

- Energy efficiency;

- Water management;

- Waste management;

- Resource conservation (materials);

- Chemical use;

- Wastewater management;

- Stormwater management;

- Social commitment;

- Economic commitment.

The preceding is applied to appraise projects including any associated infrastructure and is considered for all phases of development including planning, design, construction and operation. To help assess sustainable construction management and occupational operation commitment a number of critical documents are required to be prepared at the planning and design phase. These will need to be submitted for assessment and may include the Master Plan, Building and Infrastructure Designs, Environmental Sustainable Design (ESD) statements and Design and Landscaping Codes. Also required will be Biodiversity and Ecology Reports, Environmental Impact Assessments (EIA), Energy and Waste Management Policies and Social and Economic Commitment Strategies.

Efficient planning and design allows early identification of constraints and opportunities, streamlining delivery progression, leading to sustainable outcomes 
while achieving the project objectives. PPDS supports the project's multidisciplinary development team, manage the process. As with any new model or tool training for key members of the developer's organization or development team along with the possible engagement of an existing proficient consultant can further streamline procedures and enhance the outcomes for the precinct.

However as PPDS is based on actual case studies and reflects pragmatic project management approaches which are readily recognizable to most development managers this is not essential. Whilst this may be a potential cost saving a robust system of details and data collection must be created if the information demands of the standard are to be fully met. This feature is not uncommon to all the potential models and tools now available to the industry [12]. Evidence suggests that because PPDS is a framework process approach employed at planning and design phase the flow of data needed for assessment logically reflects the development team's usual information delivery programme.

As indicated the assessment is carried out using ccomparisons with international industry best practice which responds to the location and site specific restraints. Whilst these can include national, regional and district limitations only agreed partial recognition is given to possible accommodations for example issues linked to a developing country's supply chain capabilities.

This is a justifiable approach given that many schemes are instigated by national government development policies and international companies. Both of which often use sustainable development visages as prerequisites for environmental, social and cultural and economic development. The standard responds to these demands by using enhanced actual development project profiles and data. This offers a more rigorous framework for the protection or enhancement of environmental areas such as waterways and natural site features and social and cultural integration planning. It also provides more practical and tested means for reducing energy and water use along with greenhouse gas production. The resultant economic factors provide long term reductions of project operational and maintenance costs which can lead to improved project viability and financial success.

\section{Case study precincts features, goals and key performance areas (KPA)}

The following provides an insight into features of the assessed developments profiles and KPA's used by the Assessor when considering precinct sustainability. These translate into an ecological continuing improvement analysis which provides an overview of the general criteria, specific issues and major initiatives for medium to large mixed use precincts. Of crucial importance is precinct locality which often drives the nature of the master planned travel and tourism facility. The varied case studied schemes where a large integrated coastal resort located on Vietnam's South Central Coast, a mountain side medium hotel and villa project in southwest China and a large inland mixed use precinct in Eastern China.

Two of the schemes were underway and leant themselves to construction and occupancy interrogation. The final scheme which is an edge of city location is a 
major undertaking with a possible 7 to 10 year delivery programme. The development sites varied in topographical features, geographical conditions, and site areas, mix of facilities, accommodation type and tenure, low to high rise buildings, structural landscaping and infrastructure. All adjoined major environmental features i.e. coastal sand dunes, mountain ranges and extensive canals. Historical situates featured extensively with the precincts being in close proximity of several National Parks and UNESCO World Heritage Sites. All the locations were accessible via international airports though subject to transfer times of up to an hour in duration. The primary access road infrastructure outside of the project sites were the responsibility of provincial governments. The significance of the sites had generated major road and bridge building. Whilst the construction of this infrastructure was outside of the immediate project areas ecological impacts were considered in the assessments.

Individual precinct locations meant a variety of climatic conditions. These varied from a tropical zone known for weather extremes such as typhoons with violent winds and rain to a cooler and more temperate inland zone. The variations determined that each scheme had to have different approaches regarding comfort control and associated energy and water conservation programmes. The precincts offered a mix of 1 to 3 bedroom coastal, mountain, rural and urban villas, spa and canal detached individual residences, various 1 and 2 bedroom hotel/guest rooms and studios. These variable tenures are mainly formed in clusters of housing around a variety of facilities that include golf courses and associated maintenance stores and workshops, meeting, incentives, convention and exhibition (MICE) facilities, shops, ancillary infrastructure including, roads, as well as water and waste treatment plants. Once completed, the resorts are planned to accommodate approximately 20,000 guests and 8,000 staff/workers at any one time.

Originally secondary forestry and cultivated vegetation blanketed most of the sites. Some of the land areas were previously utilized mainly for agriculture or extraction i.e. titanium mining, making them all brownfield developments due to previous usage. Interestingly the overriding goal of improved and ongoing ecological performance arose from the client-developer seeking to implement 'sustainability' throughout the delivery process. The primary driver was for the precincts to become iconic master planned facilities in a developing country using world best practice urban planning and design principles. This it is believed leads to them becoming great places to visit, to stay and to work.

Adopting integrated development approaches resulted in decisions that provided the precincts long and short stay residents with a possible healthy lifestyle and improved quality of life. These outcomes were closely linked to improving the environments so that they deliver both privacy and quiet along with opportunities for safe and possible inspiring interaction with others. The proposed protection and regeneration of large areas of existing landscape on all the precincts should also encourage respect for the surrounding environment and its bio-diversity. 


\section{Sustainability: a master planning approach}

On these types of mixed-use precincts it is important to find an inclusive design progression, which prioritizes sustainability and eventually improved ecological performance. This approach increases the probability that sustainable outcomes are achieved. The major impacts on sustainable master planning are underlying principles set by and found in the planning and design documentation. These include the initial influences on the precinct's sustainability direction and reflect the client-developer's overview of the primary project aims and objectives.

The development teams involved had ensured that the siting of precinct buildings and associated infrastructure mitigated negative impacts on the remaining natural environment and helped in the creation of positive ecological performance improvements particularly in biodiversity. Also they are committed to reducing the environmental impacts i.e. noise and air quality loss during building activities on site through appropriate management during construction (a crucial undertaking as parts of the resort are operational). This is being achieved by encouraging the selection of contractors and subcontractors with sufficient experience to implement 'green' design and to include sustainable construction in the contractual agreement.

Whilst there are far too many initiatives to note in this paper the following conjoined principles and commitments are common to all the schemes. They included the desire to create a genuine non-gated master planned facilities using world's best practice urban planning principles. To use 'Triple Bottom Line' approaches linked to Agenda 21 sustainability principles creating precincts where guests and workers will visit and work in safety. Importantly there are collaborative processes for the management of high value conservation land areas with the local community and authorities featured. This it is believed will bring equitable social and economic advancements to a developing country, local regions and adjoining villages.

Further goals, aims and objectives flowing from the integrated development team proposals included the protection of natural attributes, character and open space roles. This was achieved by using a low residential/other building land use density on selectively cleared land. Linked to this is the dedication of extensive conservation areas and open spaces along with appropriate land management regimes that meet the conservation requirements of native plants and animals. These will mean an absorbing of impacts that might place pressure on the schemes by sensitive planning and design, innovative technical solutions and operational management by-laws. Further all the precincts provide new nodal points for equitable visitor tenure and staff employment in the adjoining regions and contributing to better opportunities for ecological outcomes interpretation and education of visitors and workers.

In responding to these influences the developments benefit from a developer providing involvement at the highest level of an organisation matched by a long term commitment to the resort precinct and facilities. Clear economic, social and environmentally sustainable goals and vision integrated into the development brief with planning and design given a key development role. This means that the already noted triple bottom line principles implicit throughout the employed 
processes driven by a corporate culture and dedicated to creating socio economic development aligned with responsible tourism can be achieved.

\section{Evaluation lessons, conclusion and recommendation}

The precincts have been assessed using an indicator benchmarking evaluation based on measures that reflect accepted good sustainable practice. Achieving on average 45 'Industry Best Practice' outcomes from the potential 50 measures noted in the PPDS assessment matrix places them at the forefront of sustainable medium to large mixed-use resort development. The remaining measures certified as industry baseline or not being measurable is an outcome commonly found on all assessments. They normally involve land disturbance ratios, energy co generation and green materials reuse. These do not lend themselves readily to improved performance outcomes due to many developing countries land availability, construction industry supply chains or regional energy provision infrastructure.

The developer for the assessed precincts is committed to ecological performance improvement. Accordingly most of the KPA's, benchmarks and measures will be revisited and benchmarked regarding operational performance improvement under an aligned EarthCheck Company Standard which has a requirement for yearly recertification. The innovative organisation challenged 'business as usual' process norms whilst recognizing that sustainable agendas require considerable inputs when developing complex mixed-use precincts. The precincts achieved high ratings due in part to the implementation of an innovative delivery strategy and long term commitments to the projects. This willingness to put forward a sustainable agenda of its own making, results in a more effective development process. It also indicates recognition of the need for continuing involvement as many sustainable inputs and their impacts take place over time and may come about by adjustment to aspects of the development. The phenomenon will most likely be seen in the critical social and economic areas.

The power of specifically developed ecological performance strategies are seen throughout the precincts planning and design development. For example the social commitment guidelines seeking to create the equitable capital necessary to aid in the process of building a strong convergent visitor and worker ethos at the precinct. As important, are the management protocols and architectural and landscape guidelines. These ensure compliance throughout the development process regarding use, delivery and quality of all buildings and related infrastructure. The enshrining of documents and the commitment of a dedicated planning and design team and consultants to aid operational users will maintain an important link between developer, consultants, the building team, owners, visitors and staff along with other stakeholders.

The developer has responded to a growing demand for improved ecological performance on travel and tourism facilities. If this call is to be managed in a sustainable manner then it is without doubt that developments must be measured in terms of impacts and eventual ongoing operation. Without the ensuing data, critical planning and design decisions cannot be made with any certainty of success. By challenging the norms of precinct delivery and opening their 
planning and design to the scrutiny of PPDS the developer indicated a willingness to reduce if not mitigate entirely the impacts of development. These actions and others measured and noted at the p suggest that for those who wish to undertake innovative, responsible and committed approaches on their projects, there must be recognition given to the merits of an open mind in their approaches in seeking and achieving sustainable outcomes.

\section{References}

[1] Berardi U, 2011: Beyond Sustainability Assessment Systems: Upgrading Topics by Enlarging the Scale of Assessment, International Journal of Sustainable Building Technology and Urban Development www.tandfonline.com (Accessed March 2012)

[2] Moore R, Hyde R and Kavanagh L, 2010: Planning, Designing and Managing Better Precincts, Sustainable Tourism - Issues, Debates and Challenges Conference Paper Crete and Santorini Greece

[3] Vietnam Agenda 21 Office, 2008: Sustainable Development Implementation in Vietnam, Hanoi Vietnam

[4] Yin R, 2003: Case Study Research - Design and Methods, (4th Edition) Applied Social Research Method Series Vol. 5 Sage Publications California USA

[5] Gill J and Johnson P, 2010: Research Methods for Managers $4^{\text {th }}$ Edition, Sage London UK

[6] Swanborn P, 2010: Case Study Research - What, Why and How? Sage London UK

[7] Silverman D, 2011: Qualitative Research $3^{\text {rd }}$ Edition, Sage London UK

[8] Bell S and Morse S, 2010: Sustainability Indicators Measuring the Immeasurable? Earthscan London UK

[9] EC3 EarthCheck 2013: www.earthcheck.org

[10] Brikeland J, 2008: Positive Development, Earthscan London UK

[11] Moore R, 2011: A Process Framework for Mixed Use Precincts RICS COBRA Conference Paper Salford University UK

[12] Cooper I and Symes M. Editors 2009: Sustainable Urban Development Volume 4 Changing Professional Practice, Routledge London UK 